\title{
Correlation of Hypothermia and Cytokines in Burned Patients
}

\author{
M. Chacón-Gómez, MD MSc, F. Martínez, MD Dc
}

Instituto Nacional de Rehabilitación, Luis Guillermo Ibarra Ibarra, México

Introduction: Burns are the most common skin lesion; they generate a local or systemic inflammatory response according to their depth and/or their burned body surface, burning agent, age and/or comorbidities $^{1}$; causing an increase in body temperature within the first 24 to 48 hours $^{2}$

CORE TEMPERATURE

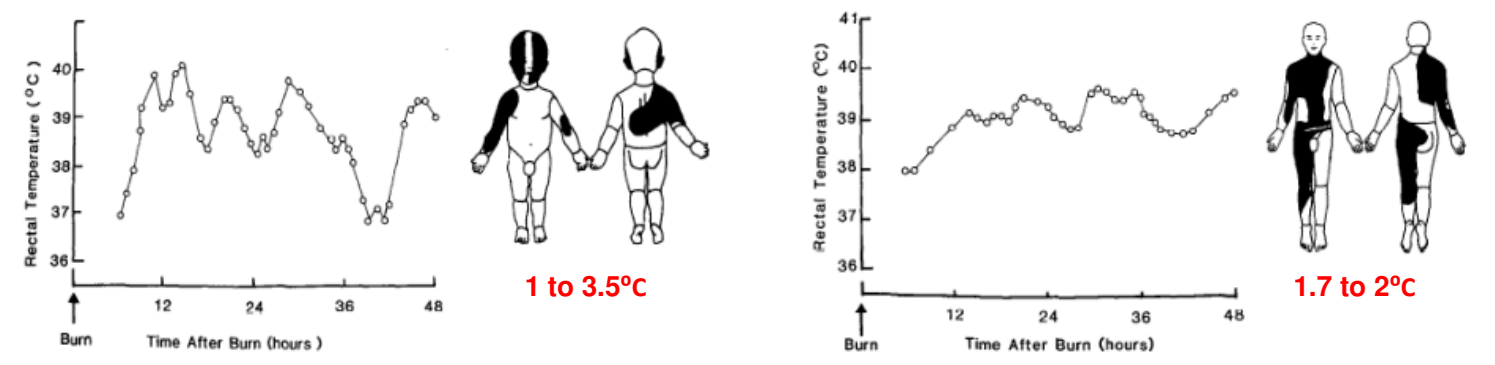

The burned population with hypothermia ${ }^{3-4}$, despite physical control before or during their hospital stay, is related to their burn body surface $^{5-6}$ or alterations in the balance of gain and loss of heat ${ }^{2}$. It has been observed that patients with hypothermia are associated with increased morbidity and mortality ${ }^{7-11}$ and no levels of proinflammatory and anti-inflammatory cytokines are known in hypothermic burned patients and their possible relationship.

\begin{tabular}{|c|c|c|c|}
\hline \multicolumn{4}{|c|}{ CYTOKINE CONCENTRATION IN HEALTHY POPULATION AND BURNED PATIENTS } \\
\hline & \multicolumn{2}{|c|}{ HEALTHY POPULATION 12} & $\begin{array}{l}\text { BURNED }{ }^{13-15} \\
\text { Temperature Unknown }\end{array}$ \\
\hline INTERLEUKIN & $\begin{array}{c}\text { CONCENTRATION } \\
(\mathrm{pg} / \mathrm{dl})\end{array}$ & CARACTERISTICS & CONCENTRATION (pg/dl) \\
\hline IL-1 & 1.4 & INDETECTABLE & $15-70 \bigcirc$ \\
\hline IL-2 & $9.4-15.4$ & \multirow{2}{*}{ NO VARIATION } & $1-8$ \\
\hline IL-10 & $9.5-16.7$ & & $10-45$ \\
\hline IL-6 & $5-20$ & \multirow{3}{*}{$\uparrow$ TEENAGERS } & $100-300$ \\
\hline TNF- $\alpha$ & $20-65$ & & $3-8$ \\
\hline INF-Y & $90-200$ & & $7-30$ \\
\hline
\end{tabular}

Methods: Study authorized by the research committee of the INRLGII in April 2014 and has informed consent for its execution.

Prospective study from April 2014 to December 2015, to determine the concentration of cytokines in a group of burned patients admitted to a Center for Specialized Care for Burn with hypothermia. Inclusion criteria: $15 \%$ to $60 \%$ of TBSA, gender indistinct, zero to 75 years old; hypothermia (temperature $\leq 36.5$ degrees) during admission or hospital stay. Exclusion: septic patients.

Determination of serum cytokines was performed in each patient, from the serum frozen at one time by a single operator, by quantitative immunoassay method for IL-6, IL-10, IL-2, INF-Y, IL1- $\alpha$ and TNF. Statistical analysis was performed using descriptive statistics analysis (ANOVA) and Spearman correlation.
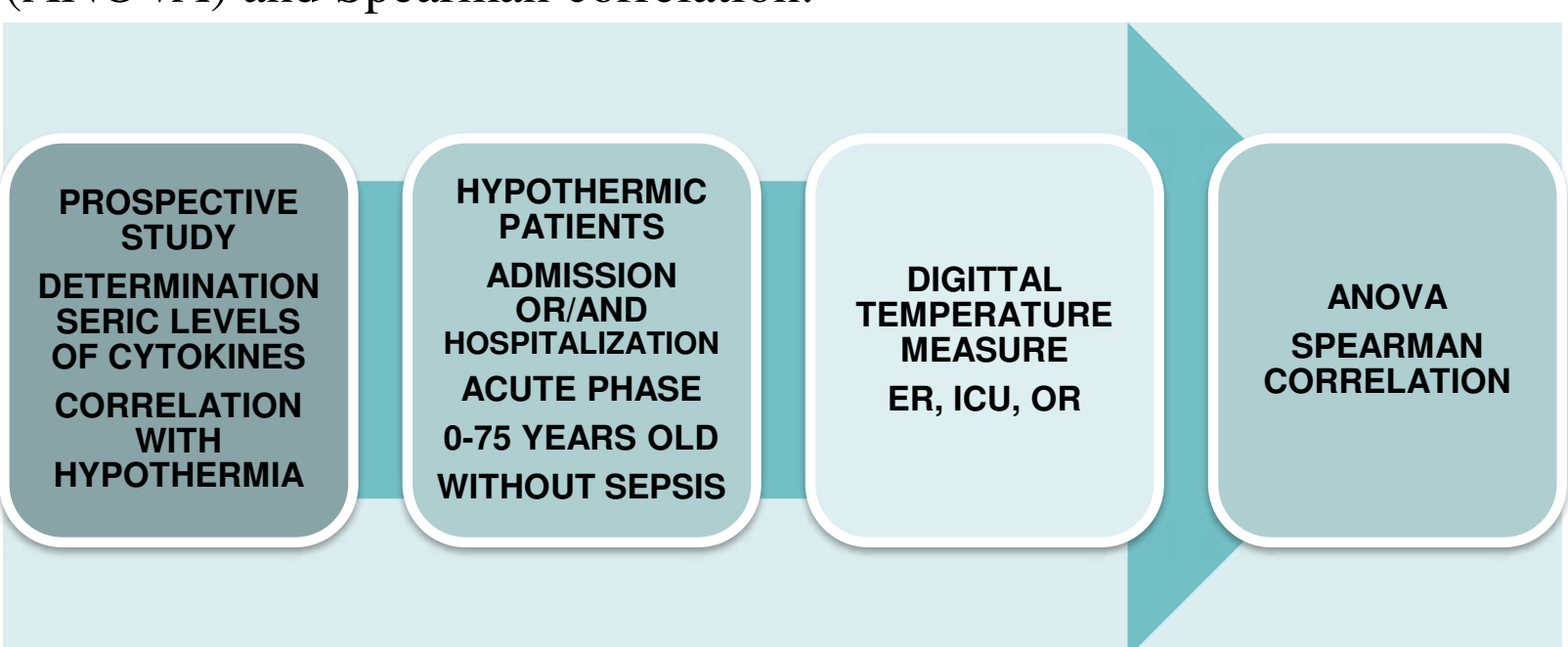

Results: A group of $10 / 18$ patients $(n=10)$ were studied; gender distribution was $40 \%(\mathrm{n}=4)$ for females and $60 \%(\mathrm{n}=6)$ for the male. Age range was 1-60 years, mean 27 years; $30 \%$ of the population was pediatric population $\leq 18$ years; and $70 \%$ adult population. $70 \%$ burn direct fire and $30 \%$ scald. TBSA between 15 to $60 \%$ with an average of $36.3 \%$. Nine patients survived (90\%), one patient died (10\%) during the study period. Temperatures range during their hospital stay was 33 to $38.9^{\circ} \mathrm{C}$, with an average of $36.03^{\circ} \mathrm{C}$. ANOVA analysis significance of $p \leq 0.001$.

Spearman correlation: gender relate to the agent that burns the skin; day taken with levels of IL-10; IL-10 with IL-2 and IL-6; IL-6 with INF- $y$ and IL-2 with INF- $y$ in the study two-tailed $p \leq$ significance of $p$ $\leq 0.5$ and 0.1 .

The deceased patient showed higher levels of IL- 6 and IL-10 compared to the rest of the population, as well as lower levels of temperature as the rest of the population; Burn extension of $20 \% *$.

\begin{tabular}{|c|c|c|}
\hline \multicolumn{3}{|c|}{ STUDY POBLATION n=10 } \\
\hline \multicolumn{2}{|c|}{ DISTRIBUTION } & MEDIA \\
\hline \multirow{2}{*}{ GENDER } & MALE $60 \%(\mathrm{~N}=6)$ & \\
\hline & FEMALE $40 \%(\mathrm{~N}=4)$ & \\
\hline AGE & 1 A 60 YEARS & 27 YEARS \\
\hline \multirow{2}{*}{ ADULT/PEDIATRIC } & ADULT $70 \% \quad(\mathrm{~N}=7)$ & \\
\hline & PEDIATRIC 30\% (N=3) & \\
\hline \multirow{2}{*}{ FIRE/SCALD } & FIRE $70 \%(N=7)$ & \\
\hline & SCALD $30 \%(\mathrm{~N}=3)$ & \\
\hline TBSA & 15 Tо $65 \%$ & $36.8 \%$ \\
\hline TEMPERATURE & 33 TO $38.9^{\circ} \mathrm{C}$ & $36.03^{\circ} \mathrm{C}$ \\
\hline \multirow{2}{*}{ LIVE/DEATH } & LIVE $90 \%(\mathrm{~N}=9)$ & \\
\hline & DEATH $10 \%(\mathrm{~N}=1)$ * & \\
\hline TEMPERATURE & INTERLEUKINE & $P$ \\
\hline \multirow{6}{*}{ DEGREES CELSIUS } & IL-6 & \multirow{5}{*}{$\leq 0.001$} \\
\hline & IL-2 & \\
\hline & IL-1a & \\
\hline & TNFa & \\
\hline & INF-Y & \\
\hline & IL-10 & 0.182 \\
\hline
\end{tabular}

\begin{tabular}{|c|c|}
\hline SPEARMAN 0.05 & SPEARMAN 0.01 \\
\hline $\begin{array}{l}\text { - SAMPLE DAY } \\
\text { - IL10, IL6,TNFa, INF } \gamma \\
\text {-GENDER } \\
\text {-ETIOLOGY }\end{array}$ & $\begin{array}{l}\cdot \text { IL6 } \\
\cdot \text { IL2, INF } \gamma\end{array}$ \\
\hline
\end{tabular}

Conclusions: Interleukins levels are different in the states of hypothermia in the burned patients.

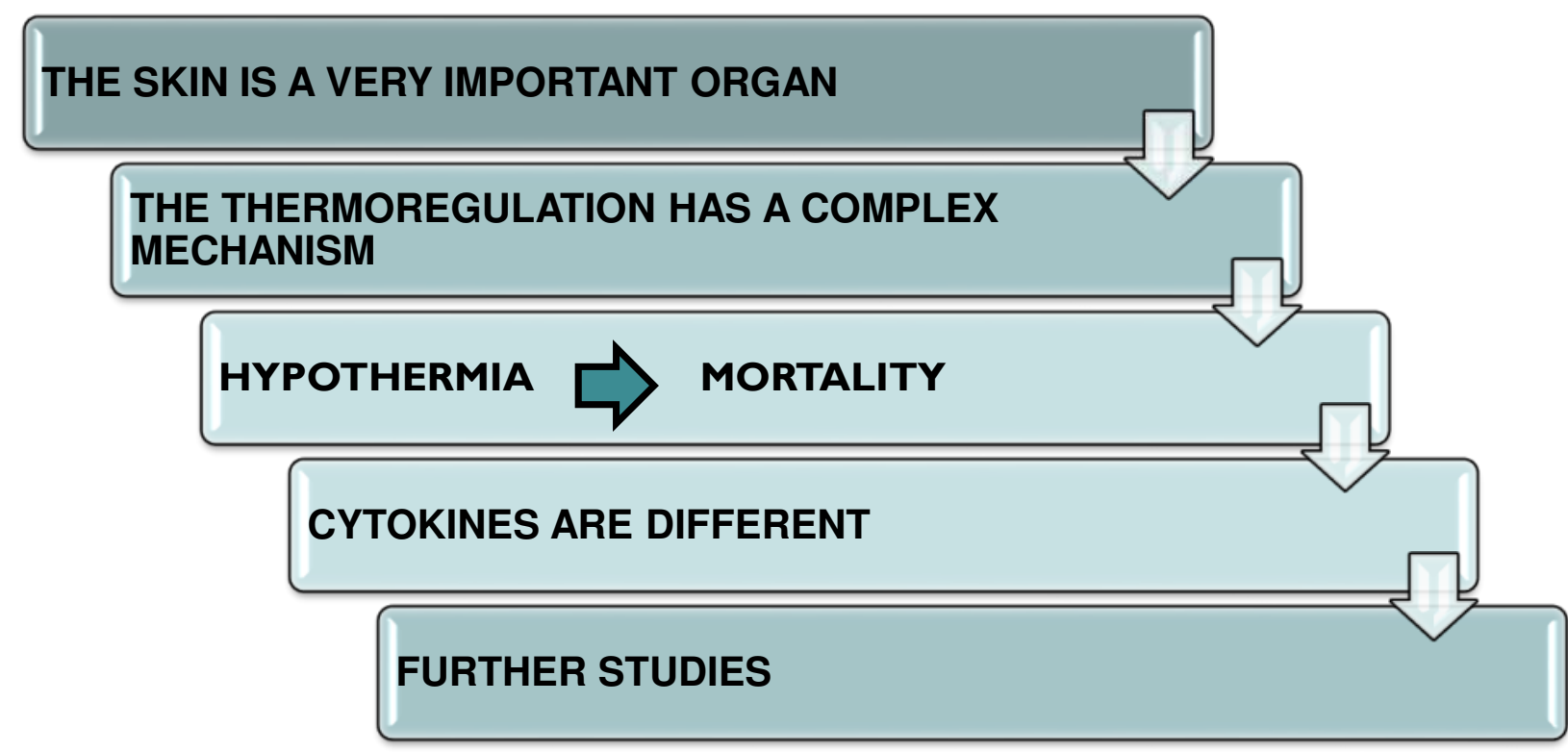

Applicability of Research to Practice: Keep warm environments for the care of burned patients.
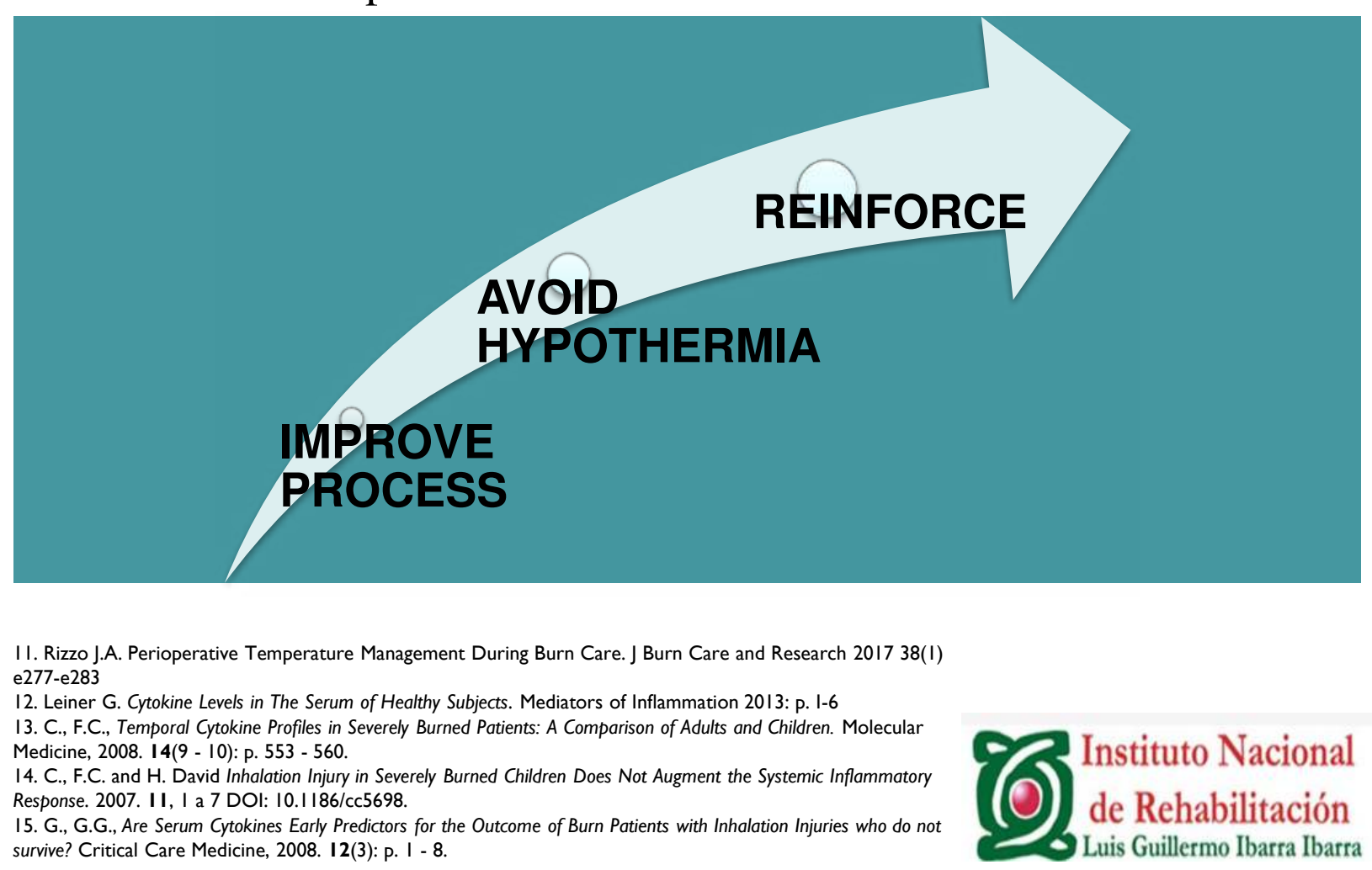